\title{
Aplicação de Modelo Computacional de Redes Neurais na previsão de dados pluviométricos no município de Paty Alferes-RJ.
}

\author{
Kelly H.F. Kawase* \\ Depto. De Matemática - PPGMMC- UFRRJ. \\ BR 465, Km 7, Seropédica - RJ, 23890-000 \\ e-mail: kellykawase@gmail.com; eluacoutinho@ hotmail.com; robsonmms@ufrrj.br
}

\begin{abstract}
RESUMO
A análise de tendências pluviométricas vem recebendo atenção especial ao longo do tempo, não só por influenciar diretamente no cotidiano, mas principalmente na produção de alimentos [4]. $\mathrm{O}$ município de Paty de Alferes tem grande expressão na produção de tomates no estado do Rio de Janeiro e os efeitos irregulares na precipitação podem ocasionar perda nas safras, comprometendo todo o mercado. Conhecer sua distribuição possibilita otimizar o potencial agrícola e os recursos hídricos, entretanto a previsão dos índices de precipitação é uma tarefa complexa pois as variáveis consideradas possuem alto grau de não linearidade, que dificulta sua previsibilidade. Fato este que tem despertado o interesse de pesquisadores para utilização de modelos preditivos baseados em Inteligência Computacional $[1,3]$.

O presente trabalho utilizou a base de dados constituída da série histórica dos valores de precipitação total mensal nos meses do verão, referente à estação Avelar, situada em Paty de Alferes - RJ, latitude $22^{\circ} 21^{\prime} \mathrm{S}$, longitude $43^{\circ} 25^{\prime}$ W e $507 \mathrm{~m}$ de altitude. Obtida junto ao Instituto Nacional de Meteorologia (INMET), no período de 1993 a 2013, totalizando 84 meses de observação. Os dados foram divididos em dois grupos consecutivos: o conjunto de treinamento com 68 amostras, com os quais a rede será treinada e o conjunto de teste independente, constituído de 16 amostras, onde será feita a validação do modelo.

O modelo computacional utilizado para a predição de precipitação pluviométrica é baseado em redes neurais de Perceptron de Múltiplas Camadas (MLP), com três camadas. Estas redes são técnicas computacionais compostas por funções de ativação não lineares nas camadas intermediárias, com capacidade de aprendizagem de padrões ocultos em um conjunto de dados e habilidade de generalização. Foi adotado um único neurônio para a camada de saída pelo fato que redes com essa especificidade tende a obter melhores resultados para a previsão um passo a frente [2].

Os valores originais da série de precipitação pluviométrica foram normalizados de modo a adaptar os dados de entrada à faixa dinâmica da função de ativação da rede neural no intervalo $[0,1 ; 0,9]$ pela expressão:
\end{abstract}

$$
\mathrm{S}_{\mathrm{i}}=\mathrm{az}+\mathrm{b}
$$

onde $S_{i}$ são os elementos da série normalizada, $z_{i}$ os da série original e a e b são constantes definidas por:

$$
\begin{aligned}
& \mathrm{a}=\frac{0,8}{\max \left(\mathrm{zi}_{\mathrm{i}}\right)-\min \left(\mathrm{zi}_{\mathrm{i}}\right)} \\
& \mathrm{b}=0,1-\mathrm{a}\left[\min \left(\mathrm{z}_{\mathrm{i}}\right)\right]
\end{aligned}
$$

onde $\max \left(z_{i}\right)$ e $\min \left(z_{i}\right)$ são, respectivamente, o máximo e o mínimo da série original.

Os parâmetros utilizados no treinamento da rede MLP foram: 300 épocas, função de ativação sigmoide, erro de treinamento 0,001 e algoritmo de treinamento Levenberg-Marquardt. Os pesos foram inicializados aleatoriamente com valores próximos de zero. Para a avaliação da capacidade de predição do modelo proposto foi utilizado a raiz do erro quadrático médio normalizado (NRMSE). O 
modelo neural foi implementado utilizando o software MATLAB (The Math Works; inc.: http//www.mathworks.com/).

Visando selecionar uma RNA que proporcionasse o melhor desempenho, fez-se um estudo variando o número de elementos do conjunto de entrada. Para cada combinação a rede foi treinada e testada visando a escolha da melhor configuração do conjunto de entrada. A validação cruzada foi utilizada de modo a evitar o problema de overfitting. A configuração com 12 neurônios na camada de entrada e 6 neurônios na camada intermediaria, obteve um erro de treinamento inferior a 1\%. Este erro foi alcançado em 9 épocas, indicando assim o potencial de convergência do algoritmo de LevenbergMarquardt.

A Figura 2 mostra o resultado obtido na predição do conjunto dos dados (conjunto teste) da precipitação total referente aos últimos 4 (quatros) verões, período de 2010 a 2013, no município de Paty de Alferes - RJ. O erro NRMSE obtido pela rede MLP foi de 0,0319, que equivale a 3,2\%.

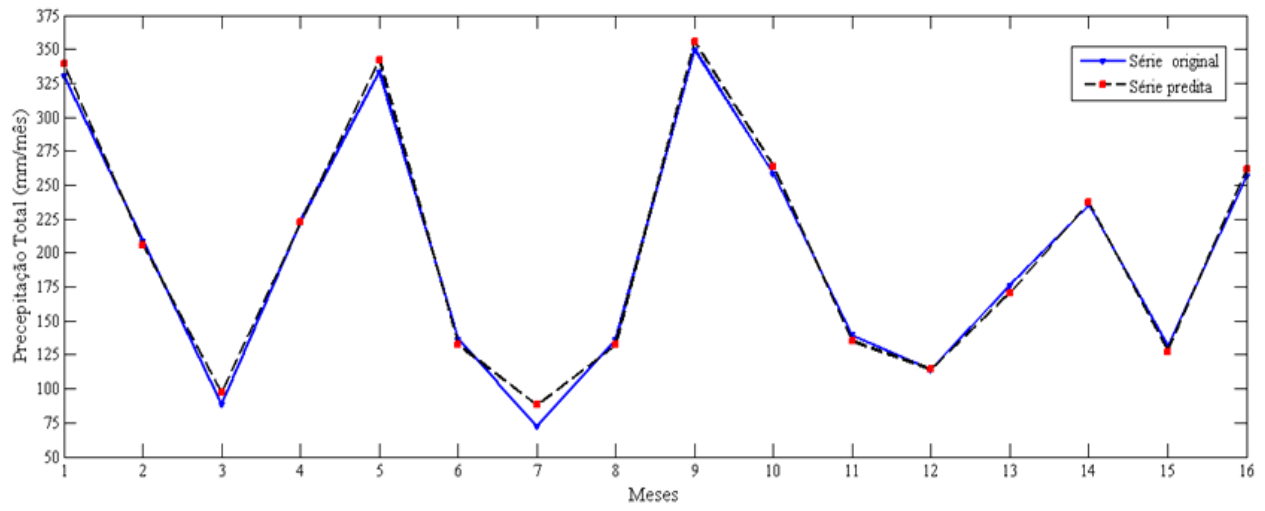

Figura 2: Predição obtida pela rede neural MLP para o conjunto de teste.

A rede neural MLP proposta neste trabalho, foi capaz de acompanhar as maiores variações de precipitação total no conjunto teste. O maior erro obtido pelo modelo foi verificado para o período de menor valor de precipitação. Embora o resultado (valor do NRMSE) tenha sido satisfatório, é pertinente comparar com outras arquiteturas de redes neurais.

Atualmente estamos aplicando novas técnicas de seleção de variáveis e utilizando outras técnicas não lineares de predição. O investimento no estudo de predição de séries temporais climáticas com padrões não lineares, é uma medida estratégica nas regiões Sul e Serrana do estado do Rio de Janeiro e o desenvolvimento da tecnologia a ser utilizada (in silico) representam, principalmente para o estado, a possibilidade de diminuição dos impactos, além de torná-la mais eficiente.

Palavras-chave: Rede Neural Artificial, Precipitação Pluviométrica, Inteligência Computacional.

\section{Referências}

[1] BELAYNEH, A; ADAMOWSKI, J; 2013. "Standard Precipitation Index Drought Forecasting Using Neural Networks, Wavelet Neural Networks, and Support Vector". Applied Computational intelligence and Soft Computing. V.2012, Article ID 794061, p. 1-13.

[2] HAYKIN, S. "Neural Networks and Learning Machines”. Prentice Hall, 2008.

[3] SANTHANAM, T. SUBHAJINI, A.C; "Na Efficient Weather Forecasting System using Radial Basis Function Neural Network". Journal of computer Science, p. 962-966., 2011.

[4] TUCCI, C.E.M. Impactos da Variabilidade Climática e dos Usos do Solo nos Recursos Hídricos. ANA, 150 p. Relatório Técnico. Brasília, 2002. 